\title{
Glyphosate, a cancer generator? - mini review
}

Keywords: glyphosate, cancer, carcinogenic agent, shikimic acid, non-selective herbicide

\section{Introduction}

Glyphosate is an herbicide and one of the most widely used. Some products containing glyphosate control aquatic plants. Glyphosate comes in many forms, including an acid and several salts. These can be either solids or an amber-colored liquid.

Glyphosate is a non-selective herbicide, it stops a specific enzyme pathway, the shikimic acid pathway. The shikimic acid pathway is necessary for plants and some microorganisms. Pure glyphosate is low in toxicity, but products usually contain other ingredients which can make it more toxic. Products containing glyphosate may cause eye, skin, nose and throat irritation. The vast majority of glyphosate leaves the body in urine and feces without being changed into another chemical. A committee of scientists working for the International Agency for Research on Cancer of the WHO, evaluated fewer studies and reported that glyphosate is probably carcinogenic. ${ }^{1}$

\section{Exposure to glyphosate-based herbicides (GBHs)}

The potential carcinogenic properties of glyphosate are the subject of widespread scientific debate. The US Environmental Protection Agency said in a 2017 draft risk assessment that the herbicide "is not likely to be carcinogenic to humans, while the "European Food Safety Authority"2 maintains a similar stance. In 2015, however, the World Health Organization's International Agency for Research on Cancer classified glyphosate as "probably carcinogenic to humans". ${ }^{1}$ Moreover, the chemical has triggered multiple lawsuits from people who believe that exposure to the herbicide caused their Non-Hodgkin's Lymphoma. $^{3}$

The authors of the University of Washington report analyzed all published studies on the impact of glyphosate on humans. Co-author and doctoral student Rachel Shaffer said in a statement: "This research provides the most up-to-date analysis of glyphosate and its link with Non-Hodgkin Lymphoma, incorporating a 2018 study of more than 54,000 people who work as licensed pesticide applicators". Focusing on data relating to people with the "highest exposure" to the herbicide, the researchers concluded that a "compelling link" exists between glyphosate exposure and a greater risk of developing Non-Hodgkin Lymphoma. ${ }^{3}$ Francis Martin, a biosciences professor at the University of Central Lancashire, called the debate over the safety of glyphosate "important", however, he stressed that the University of Washington's report "highlights the need for new, well-designed and robust studies at appropriate exposure levels, adding "The number of robust studies in the literature examining this question is pathetically small".

An evaluation by several members of a scientific advisory panel on glyphosate at the United States Environmental Protection Agency (EPA), teamed up to conduct their own meta-analysis. Their paper, published online February 10, 2019, in the journal "Mutation Research", reports a $41 \%$ increase in the risk of Non-Hodgkin Lymphoma associated with exposure to glyphosate.

Glyphosate continues to generate controversy. ${ }^{4}$ Surprisingly, the EPA, recently, reevaluated glyphosate's carcinogenic potential. To
Volume I I Issue I - 2020

Hajj Adel Anis

Cedars Jebel Ali International Hospital, UAE

Correspondence: Hajj Adel Anis, Medical Oncologist at Cedars Jebel Ali International Hospital, 9370 Rue Lajeunesse, Montreal, UAE, Tel 438992 55I6, Email ahajj@dr.com

Received: November 19, 2019 | Published: February 05, 2020

help craft their assessment, the agency sought recommendations from a group of experts called the Federal Insecticide, Fungicide, and Rodenticide Act (FIFRA) Scientific Advisory Panel. Ultimately, after reviewing the evidence, the EPA determined that glyphosate is "not likely to be carcinogenic to humans". However, some members of the panel disagreed with the EPA's process. Because of their dissatisfaction with EPA's report, the three scientists, Luoping Zhang, $\mathrm{PhD}$, of the University of California, Berkeley; Emanuela Taioli, MD, $\mathrm{PhD}$, of the Icahn School of Medicine at Mount Sinai, New York; and Lianne Sheppard, PhD, of the University of Washington, Seattle, decided to pursue related research to dig further into the issues. In their meta-analysis, the researchers incorporated data from 5 casecontrol studies, plus data from the Agricultural Health Study (AHS), a large cohort study conducted over a period of 25 years that collected data from licensed pesticide applicators in Iowa and North Carolina. "This is the latest in a series of meta-analyses that have been done on this topic", said epidemiologist Laura Beane Freeman, PhD, who works at the National Cancer Institute. Though there were few new data, this paper differs from previous analyses because the researchers focused on the highest exposure levels whenever possible.

\section{Conclusion}

Despite numerous studies regarding the dangers resulting from the extensive use of glyphosate, ${ }^{5}$ it is not possible to attribute a clear and unambiguous definition to glyphosate, especially regarding its potentially harmful effects on humans. ${ }^{4}$

It is also evident that new studies and independent research must be performed in order to clearly define the seriousness of glyphosate exposure to carcinogenicity and genotoxicity. In fact, there is a too great a discrepancy between the opinions of the various scientific institutions, mainly because of their different economic and social interests. The controversy and the debate are expected to continue.

\section{Acknowledgments}

None.

\section{Conflicts of interest}

The authors declare there are no conflicts of interest.

\section{References}

1. Daniel Cressey. Widely used herbicide linked to cancer. 2015.

2. Tarazona JV, Court-Marques D, Tiramani M, et al. Glyphosate toxicity 
and carcinogenicity: a review of the scientific basis of the European Union assessment and its differences with IARC. Arch Toxicol. 2017;91(8):2723-2743.

3. Chang ET, Delzell E. Systematic review and meta-analysis of glyphosate exposure and risk of lymphohematopoietic cancers. J Environ Sci Health B. 2016;51(6):402-434.
4. Acquavella J, Garabrant D, Marsh G, et al. Glyphosate epidemiology expert panel review: a weight of evidence systematic review of the relationship between glyphosate exposure and non-Hodgkin's lymphoma or multiple myeloma. Crit Rev Toxicol. 2016;46(sup1):2843.

5. Weaver CH. Jury Determines That Monsanto's Roundup Responsible for Lymphoma. 2018 